Article

\title{
Improved Detection of Tiny Macroalgae Patches in Korea Bay and Gyeonggi Bay by Modification of Floating Algae Index
}

\author{
Ahmed Harun-Al-Rashid ${ }^{1,2}$ (D) and Chan-Su Yang ${ }^{1,2,3, *}$ \\ 1 Marine Security \& Safety Research Center, Korea Institute of Ocean Science \& Technology, \\ Busan 49111, Korea; rashid@kiost.ac.kr \\ 2 Integrated Ocean Sciences, University of Science \& Technology, Daejeon 34113, Korea \\ 3 Department of Convergence Study on the Ocean Science and Technology, \\ Ocean Science and Technology School, Korea Maritime and Ocean University, Busan 49111, Korea \\ * Correspondence: yangcs@kiost.ac.kr; Tel.: +82-10-3478-8637
}

Received: 26 July 2018; Accepted: 1 September 2018; Published: 16 September 2018

\begin{abstract}
This work focuses on the detection of tiny macroalgae patches in the eastern parts of the Yellow Sea (YS) using high-resolution Landsat-8 images from 2014 to 2017. In the comparison between floating algae index (FAI) and normalized difference vegetation index (NDVI) better detection by FAI was observed, but many tiny patches still remained undetected. By applying a modification on the FAI around $12 \%$ to $27 \%$ increased and correct detection of macroalgae is achieved from 35 images compared to the original. Through this method many scattered tiny patches were detected in June or July in Korea Bay and Gyeonggi Bay. Though it was a small-scale phenomenon they occurred in the similar period of macroalgal bloom occurrence in the YS. Thus, by using this modified method we could detect macroalgae in the study areas around one month earlier than the previously used Geostationary Ocean Color Imager NDVI-based detection. Later, more macroalgae patches including smaller ones occupying increased areas were detected. Thus, it seems that those macroalgae started growing locally from tiny patches rather than being transported from the western parts of the YS. Therefore, this modified FAI could be used for the precise detection of macroalgae.
\end{abstract}

Keywords: macroalgal bloom; Landsat-8; floating algae index (FAI); Korea Bay; Gyeonggi Bay

\section{Introduction}

Vigorous proliferation of macroalgae is usually referred to as a macroalgal bloom (MAB) which generally occurs in the eutrophic waterbodies like bays, lakes, coastal waters, etc. [1,2]. It is now a worldwide issue occurring in many parts of the marine environment including the Yellow Sea (YS) [3-6]. Ulva prolifera is the major macroalgae species which causes MAB in the YS [7]. During its heavy growth, large free-floating forms are produced that can be detected from satellite images like other floating macroalgae by using various types of vegetation indices. Although MAB was a common phenomenon in the YS, in 2008 it attracted mass public attention for the first time due to massive bloom and sudden beaching in huge amounts in the coastal regions of Qingdao, China [8]. Afterwards, it progressively recurred in the western YS and adjacent waters [9].

In the previous work [10] monthly distribution and hourly shifts of MAB were detected over a large area in the YS using the high temporal-resolution Geostationary Ocean Color Imager (GOCI)-based normalized difference vegetation index (NDVI) data [10]. In addition to that during the last few years some macroalgae patches were also detected in Korea Bay and Gyeonggi Bay, far apart from the YS [10]. However, those not received much attention in academic circles due to their limited coverage and duration compared to those in the YS. Nevertheless, their accurate detection 
is necessary to know the current status as well as to predict their future distribution. In particular, tiny patches (smaller than the spatial resolution of GOCI, $500 \mathrm{~m}$ ) could not be detected through the previous study [10]. Thus, it could not be also determined whether those macroalgae patches in the western coastal regions of the Korean Peninsula started growing locally, or were transported from the YS and then bloomed. Therefore, higher resolution $(30 \mathrm{~m})$ Landsat-8 images are used in this study in order to detect the tiny patches of macroalgae.

NDVI is a widely used index among the vegetation indices for satellite detection of floating macroalgae [11]. Despite that, by using the floating algae index (FAI) better and stable results in macroalgae detection can be attained in different weather conditions such as clear, hazy and sun glint compared to the NDVI [12]. Various types of surface floating macroalgaes like green macroalgae and brown macroalgae can be detected using this FAI [12]. Researchers considered 0 to negative values of FAI as the absence of macroalgae, and 0.02 to above values of FAI as $100 \%$ macroalgae concentration [12]. However, the water in the YS is a typical Case II type of optically complex water [13], which results in a range of reflectance values differing largely even in areas under the coverage of a single Landsat- 8 image. Thus, it also restricts the use of a single scene-wide threshold value of FAI to detect most of the small patches and portions of larger patches. Therefore, in this study we considered precise detection of tiny patches of macroalgae, and thereby modified the FAI (hereafter mod-FAI). In the following section the study area and the method of obtaining mod-FAI is summarized, and in Section 3 the comparative results of macroalgae detection by the vegetation indices in several images are shown. In Section 4 the mod-FAI based results are then compared with the FAI and NDVI, and discussed accordingly. Finally, the paper is summarized in Section 5.

\section{Materials and Methods}

In this study, the occurrences of macroalgaes from 2014 to 2017 are investigated in Korea Bay and Gyeonggi Bay regions. These areas are located at the north-eastern side of the YS (Figure 1). Landsat-8 scenes designated by path/row 117/33, 118/32, and 118/33 cover Korea Bay, and 116/34 and 117/34 cover Gyeonggi Bay (Figure 1). Korea Bay is a large sea area occupying a shallow basin (depth $\leq 50 \mathrm{~m}$ ) [14]. Gyeonggi Bay is also a shallow sea area with average depth of less than $40 \mathrm{~m}$ located on the west of the Korean Peninsula $[15,16]$. Due to shallow basins and their geographical location, the environment in these areas is highly influenced by strong tidal currents and winds which might also affect the shift and distribution of macroalgae [14,15,17].

This study uses Landsat-8 satellite data which acquires images of the entire earth's surface and oceans with a revisit period of 16 days [18,19]. Images are acquired through the collaboration of the National Aeronautics and Space Administration (NASA) and United States Geological Survey (USGS) [9]. The images comprise 11 bands covering visible, near infrared (NIR), short-wave infrared (SWIR), and thermal infrared wavelengths of the spectrum [9]. Its high spatial resolution (30 $\mathrm{m})$ and wide swath $(185 \mathrm{~km})$ allow precise detection and monitoring of macroalgae in the study areas [9].

The FAI data were generated using the Rayleigh corrected reflectance (Rrc) of red (RED), NIR and SWIR bands [12]. The Atmospheric Correction for Operational Land Imager (OLI) 'lite' software (ACOLITE, ver. 20170718.0) was used for data processing [20]. It is a stand-alone version of Interactive Data Language (IDL) developed by the Royal Belgian Institute of Natural Sciences (RBINS) for the processing of Landsat-8 and Sentinel-2 images [21,22]. The ACOLITE was used because of its fast and automatic processing capability of image data for marine and inland water applications [22]. During data conversion, standard atmospheric parameters were used. The Rayleigh correction was done with the help of 6SV-based lookup table, illumination, and viewing geometry data (sun and sensor zenith, and azimuth angles) [22,23]. Finally, the FAI was calculated according to the following equation [12]:

$$
\mathrm{FAI}=\mathrm{R}_{\mathrm{NIR}}-\mathrm{R}_{\mathrm{RED}}-\left(\mathrm{R}_{\mathrm{SWIR}}-\mathrm{R}_{\mathrm{RED}}\right) \times \frac{\left(\lambda_{\mathrm{NIR}}-\lambda_{\mathrm{RED}}\right)}{\left(\lambda_{\mathrm{SWIR}}-\lambda_{\mathrm{RED}}\right)}
$$


Here, R represents the Rrc of NIR, RED and SWIR bands (bands 5, 4 and 6, respectively). The symbol $\lambda$ represents wavelength which are 865, 655 and $1609 \mathrm{~nm}$ for the NIR, RED and SWIR bands, respectively.

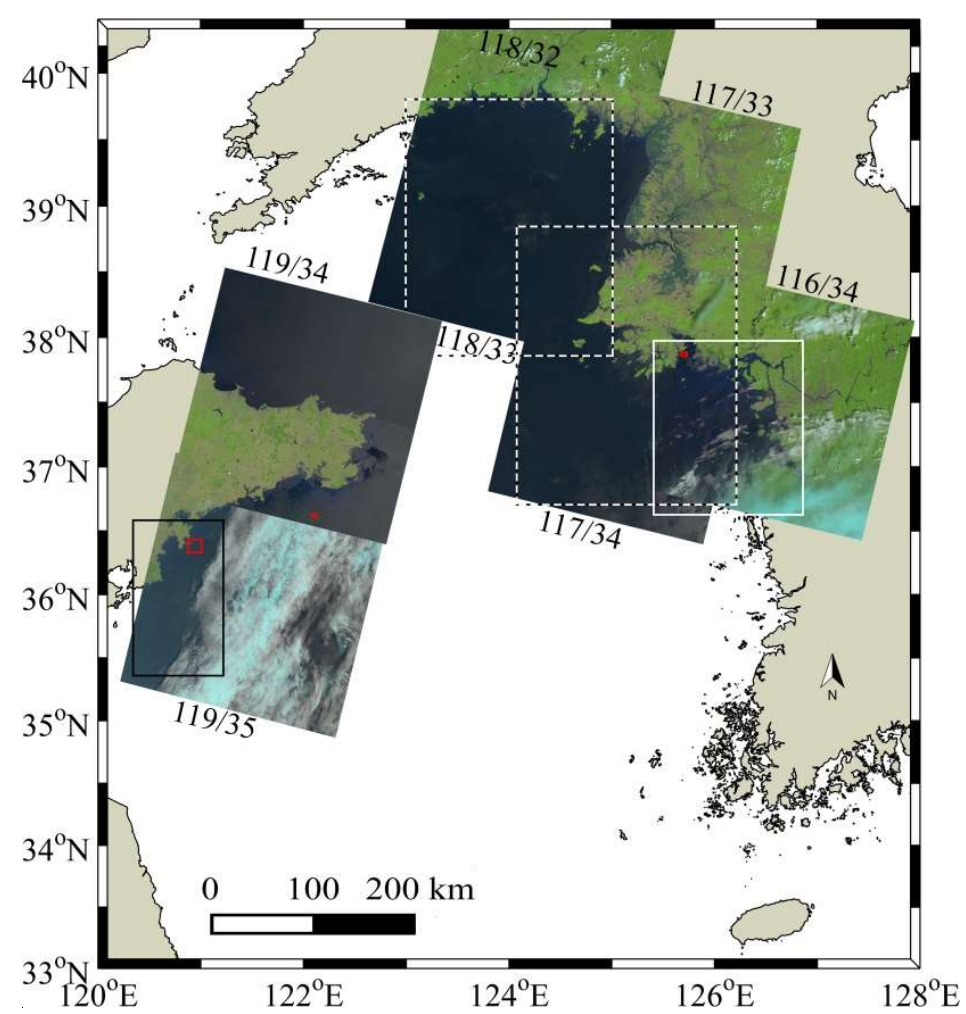

Figure 1. Study area map displaying Landsat-8 path/row coverage by some natural colour composite images (RGB 4, 3 and 2 respectively for 655, 561 and $482 \mathrm{~nm}$ ) on 2 August 2014 (116/34), 6 June 2014 (117/33 and 117/34), 5 August 2016 (118/32 and 118/33), 25 June 2016 (119/34), and 25 July 2015 (119/35). Three large white rectangles indicate the study areas, and the three small red rectangles and the large black rectangle indicate the ROI for showing the comparison between detection results by different vegetation indices: NDVI, FAI, and mod-FAI.

In the FAI, the RED and SWIR bands are used to form a baseline, which is then subtracted from the NIR reflectance [11]. This subtraction takes care of perturbations from many sources and allows image-independent thresholds to detect and quantify floating algae [11]. During this study though large patches of macroalgae are suitably detected, many tiny patches still remain undetected by applying the generalized minimum threshold value of 0 [12] on FAI (shown later in this manuscript). This emphasizes the importance of using such a vegetation index which could at least accurately detect small patches of macroalgaes, and we have modified the FAI accordingly.

A series of Landsat- 8 images covering the study areas during the study period were first downloaded from the USGS archive [24] and processed to FAI and mod-FAI after checking the existence of macroalgae patches with reference to the green colour patches in the natural colour composite images (RGB bands 4, 3 and 2). The macroalgae-containing images as used in this study are listed in Table 1. Cloud masking was not directly applied to the images due to the macroalgae detection capability of FAI under thin clouds [12]. Rather, regions of interest (ROIs) were masked out including the visible macroalgae patches under very thin clouds. The conversion of image digital number to Rrc and subsequent calculation of FAI were accomplished using the radiometric calibration module of ACOLITE which performs the calibration by automatic loading the metafile (MTL.txt) of the respective Landsat- 8 imagery bundle. The general process flow of macroalgae detection is shown in Figure 2. 
Table 1. List of Landsat-8 images used in this study.

\begin{tabular}{cccc}
\hline Path & Rows & Date & Coverage \\
\hline 116 & 34 & 1 July 2014 & Gyeonggi Bay \\
116 & 34 & 2 August 2014 & Gyeonggi Bay \\
116 & 34 & 1 May 2015 & Gyeonggi Bay \\
116 & 34 & 4 July 2015 & Gyeonggi Bay \\
116 & 34 & 6 July 2016 & Gyeonggi Bay \\
116 & 34 & 22 July 2016 & Gyeonggi Bay \\
117 & 33,34 & 6 June 2014 & Korea Bay, Gyeonggi Bay \\
117 & 33,34 & 8 July 2014 & Korea Bay, Gyeonggi Bay \\
117 & 33,34 & 11 July 2015 & Korea Bay, Gyeonggi Bay \\
117 & 33,34 & 27 July 2015 & Korea Bay, Gyeonggi Bay \\
117 & 33,34 & 12 August 2015 & Korea Bay, Gyeonggi Bay \\
117 & 33,34 & 28 August 2015 & Korea Bay, Gyeonggi Bay \\
117 & 33,34 & 1 August 2017 & Korea Bay, Gyeonggi Bay \\
117 & 33 & 29 July 2016 & Korea Bay \\
117 & 33 & 14 June 2017 & Korea Bay \\
117 & 34 & 15 October 2015 & Gyeonggi Bay \\
118 & 32,33 & 5 August 2016 & Korea Bay \\
118 & 32,33 & 23 July 2017 & Korea Bay \\
118 & 32 & 21 June 2017 & Korea Bay \\
118 & 33 & 13 June 2014 & Korea Bay \\
118 & 33 & 29 June 2014 & Korea Bay \\
118 & 33 & 16 August 2014 & Korea Bay \\
118 & 33 & 19 August 2015 & Korea Bay \\
118 & 33 & 20 July 2016 & Korea Bay \\
119 & 34 & 25 July 2016 & Yellow Sea (Qingdao, China) \\
119 & 35 & 25 July 2016 & Yellow Sea (Qingdao, China) \\
\hline & & &
\end{tabular}

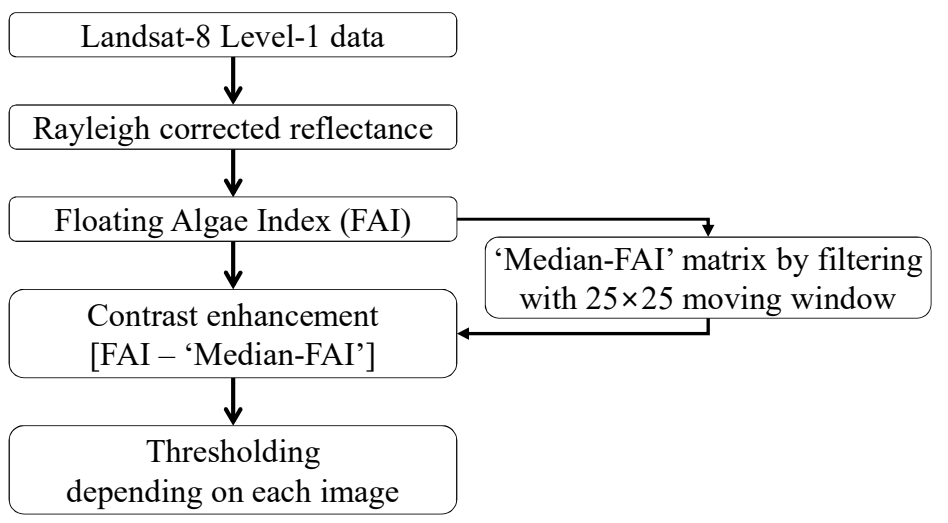

Figure 2. Flow diagram for the modified FAI-based macroalgae detection.

Water in the YS and adjacent areas are atmospherically highly variable which results in wide ranges of sea pixels' reflectance values in satellite images. This creates conflicts in differentiation of macroalgae pixels from the water pixels, especially in the hazy areas where many sea pixels possess positive FAI values. Therefore, for better detection of macroalgae the contrast between macroalgae pixels and surrounding ocean pixels need to be increased through reduction of high variations in the background (sea) pixels. This can be performed by subtracting each pixel's median value for a specified surrounding region from the respective pixel's FAI value (median filtering). The median filter is one of the simplest and the most common non-linear smoothing filters for removing noise from images [25-30]. The essential idea of a moving median filter is to replace the value of the centre pixel by the median value of the predefined number of neighbouring pixels. All pixel values in the neighbourhood are first sorted ascendingly; then the central pixel is replaced by a value that is more typical for the neighbourhood (the median value); and thus pixels with runaway intensities are 
eliminated [31]. The advantage of this method is that only an odd number of data points need to be selected [32]. The median value in the given group of data points is then registered as the data point of interest in the filter set of data [33]. The next group is selected by advancing one data point from the previous data point of interest, and this process is repeated until the final data point is reached [33]. The only drawback is that in the case of a $(2 n+1) \times(2 n+1)$ size of moving window, the $n$ number of pixels along boundaries of image axes could not be calculated. However, due to the high spatial resolution and wide swath of Landsat-8, very small proportion of image areas is thus ignored for calculation during this process. Hence, they have negligible effect on the detection results. Therefore, in the current study the Landsat-8 FAI data were modified using the moving median filter.

Through the proposed modification of FAI by applying a moving median filter [7], individual pixels could be suitably classified based on whether they contain macroalgae or not. At first a background ocean signal for a specific localized region is determined and subtracted from the respective FAI value (Figure 2). More precisely, the median FAI value is calculated for a square box region centred on the pixel-of-interest. Through the thorough observations we found that for the data used in this study, the $25 \times 25$ pixel box size gives the best detection results for most of the tiny macroalgae patches with a minimum false classification of ocean pixels as macroalgae. Subsequently, this median value is subtracted from the FAI value of the corresponding pixel forming the proposed mod-FAI. Thus, scaling of all non-algae pixels to values close to zero was accomplished. Finally, the macroalgae pixels were detected through thresholding the mod-FAI. The image-specific threshold value for the mod-FAI was determined by the exclusion method according to Garcia et al. 2013 [34]. For that purpose, multiple oceanic regions in the images which visually did not appear to have macroalgae or cloud pixels were selected based on comparison with the respective true colour composite image. Then, the threshold was computed by finding the value that is greater than a specified proportion of ocean pixels from the selected ocean regions in the mod-FAI image [34].

\section{Results}

As precise detection of tiny macroalgae patches is the target of this study, comparison of their detection results by different vegetation indices are shown mainly for small geographical areas for better visibility rather than presenting the detection results for the whole images or large area ROIs. However, in Figure 3 the detection of macroalgae patches by several indices between different satellites are presented for the whole image area coverage of Landsat-8 in order to show the overall comparison. The detection results of macroalgae by FAI and mod-FAI of path/row 119/35 on 25 July 2015 are shown as Figure $3 b, c$, respectively, and the macroalgae detection in the respective area of GOCI based NDVI is shown as Figure 3a. Although cloud masking was not applied to the images, for the clarity of comparison here the areas containing clouds (except macroalgaes under thin clouds) are manually masked out. Similarly, the lands in the images are also masked out. In the NDVI image some macroalgae patches (dark red pixels) covering small areas are detected, whereas considerably more areas are detected as macroalgae in the high spatial resolution Landsat- 8 based FAI image. However, still many small patches of macroalgae could not be detected which were acceptably detected by the mod-FAI. Moreover, overdetection of sea pixels as macroalgae is not observed in this mod-FAI image as were in the FAI (very large red patches).

In Figure 3a, small ROI area in the sub-images are marked by small black rectangles, and the detection results of various vegetation indices under that area are enlarged in Figures 4 and 5 for better visual comparison. As the water in the YS is optically complex, the natural colour composite images in Figure 4a,b are shown after different intensity stretching for clear visualization of the macroalgae patches in different locations of the image. From Figure $4 \mathrm{c}$ it can be seen that the contrast between macroalgae and surrounding sea pixels in the FAI image is not very high, which can be also noticed clearly from the colourmap of FAI (Figure 4e). On the contrary, the overall contrast of macroalgae and sea pixels is distinct in the mod-FAI (Figure $4 \mathrm{~d}$ ), and the pixel values are also more scaled (Figure 4f). From the observation of Figure 5 it is found that, by applying threshold 0 on FAI, 
an area of around $13.71 \mathrm{~km}^{2}$ is detected as macroalgae, whereas in the mod-FAI an area of around $16.74 \mathrm{~km}^{2}$ is detected as macroalgae by applying the threshold of 0.001 . Thus, about $23 \%$ more area is discriminated as macroalgae by the modified index than that of the FAI (Figure 5c). However, many images in the study areas during the study period were hazy. Moreover, most of the established studies on satellite-based macroalgae detection are done in the YS where the growth of macroalgae is more vigorous than those in Korea Bay and Gyeonggi Bay. Therefore, first we have tested the proposed method on several images covering the YS (Figures 3-7). From the observation of Figure $4 \mathrm{~d}$ it can be seen that some long, slender patches of macroalgaes cannot be observed clearly in the southward area of the FAI image. In the contrast-stretched colour RGB image (Figure 4b), some more smaller macroalgal patches are seen clearly in the southward area of the image which could not be detected in the respective FAI image. Noticeably, in the respective areas of mod-FAI image (Figure $4 \mathrm{~d}$ ) those patches can clearly be identified similar to the shapes as seen in the true colour composite images which became possible due to the enhancement of image contrast. The comparisons are further clearly shown as only detected macroalgae pixels (Figure 5). The mod-FAI shows more detection of tiny patches (red pixels in Figure 5c) whereas FAI showed much misdetection of sea as macroalgae (large blue patches at the top left corner of Figure 5c).

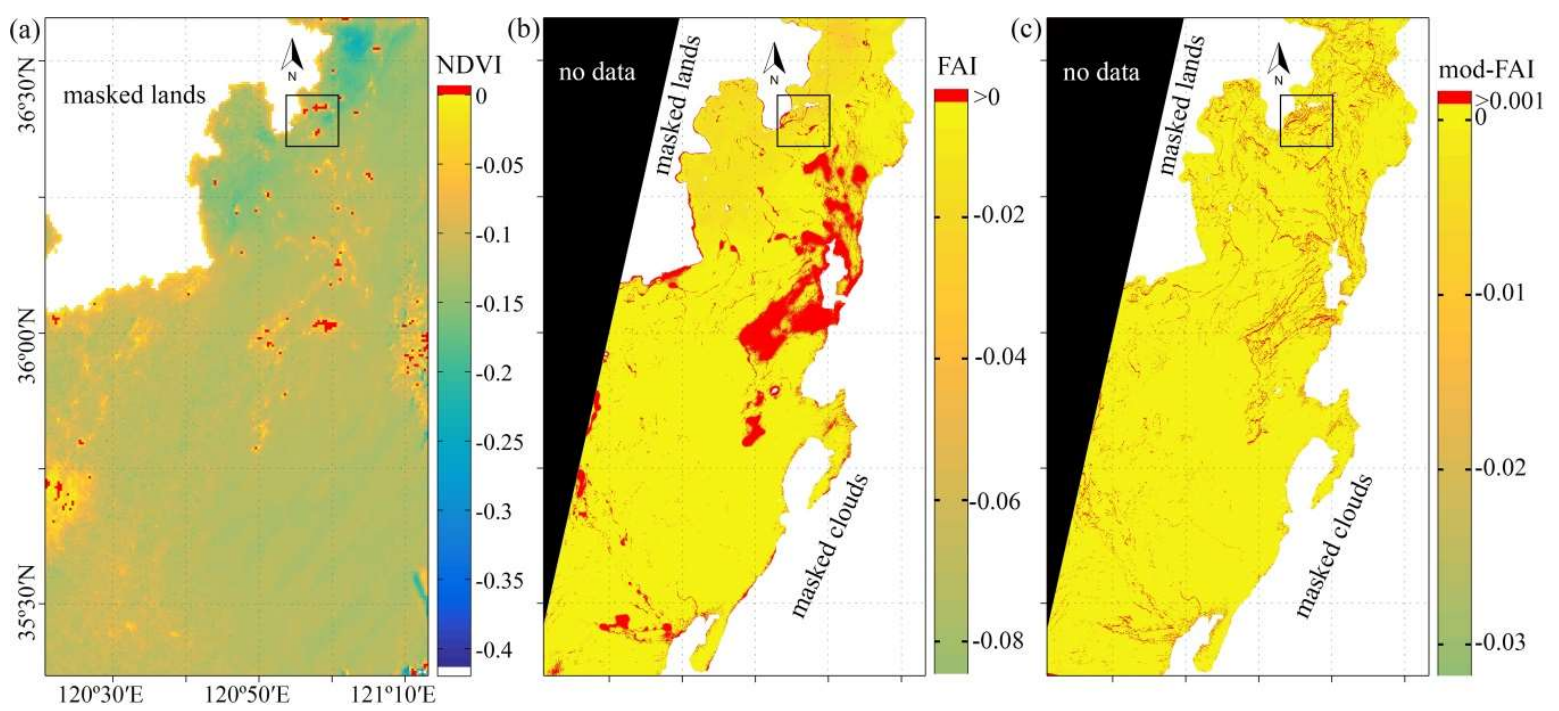

Figure 3. Comparison of macroalgal bloom detection results (dark red) between (a) Geostationary Ocean Color Imager (GOCI) normalized difference vegetation index (NDVI), (b) Landsat-8 FAI, and (c) Landsat-8 modified FAI. The GOCI image was acquired on 25 July 2015 03:31 UTC, and the Landsat-8 based images represent for ROI area inside path/row 119/35 image (large black rectangle in Figure 1) at 02:30 UTC on the same date. The small ROI area inside each image is marked by a black rectangle.

The detection results for some other images covering different areas are shown for small ROIs in Figures 6 and 7. From Figure 6 it can be seen that an area of around $0.69 \mathrm{~km}^{2}$ is detected as macroalgae in the displayed area of Landsat-8 NDVI image whereas about $17.4 \%$ more detection $\left(0.81 \mathrm{~km}^{2}\right)$ is obtained from the respective FAI. Progressively, from the mod-FAI an area of about $1.1 \mathrm{~km}^{2}$ is detected as macroalgae due to more detection of tiny patches. Although very few patches were not detected by the mod-FAI as were in the FAI, the overall detection result in the proposed method is improved. The detection result for a small ROI in another image is shown in Figure 7. It can be seen that the full area of ROI is wrongly detected as macroalgae in both of NDVI and FAI which might have caused from the haziness of those image pixels. Despite that, macroalgae were correctly detected in the proposed mod-FAI image. Similarly, we have also compared the detection results in other areas of these images as well as different images (not shown here) and found similar good detection results by the proposed method in terms of the detection of small patches and avoidance of overdetection in hazy areas, which signify its suitability for the study areas. 

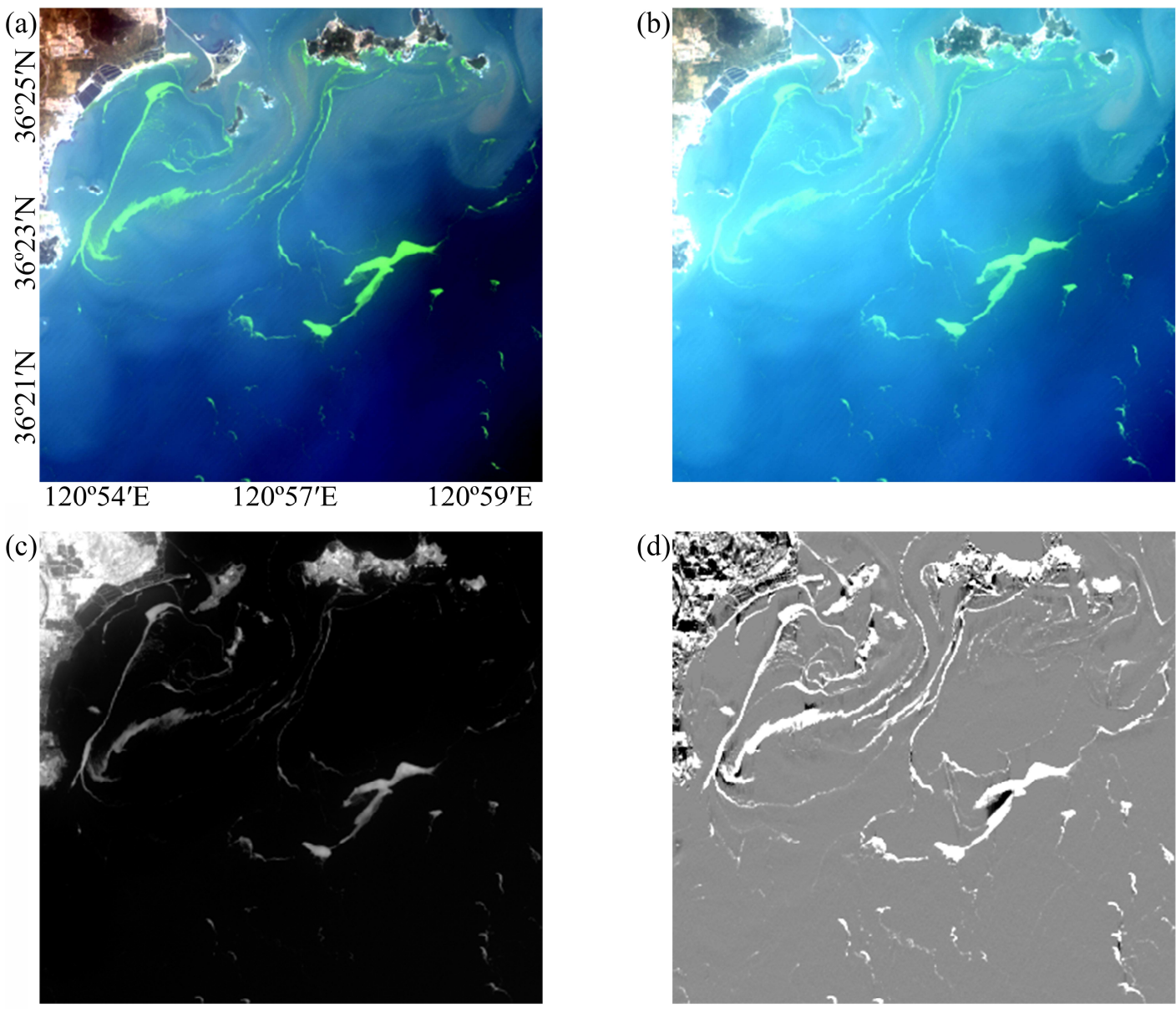

(e)
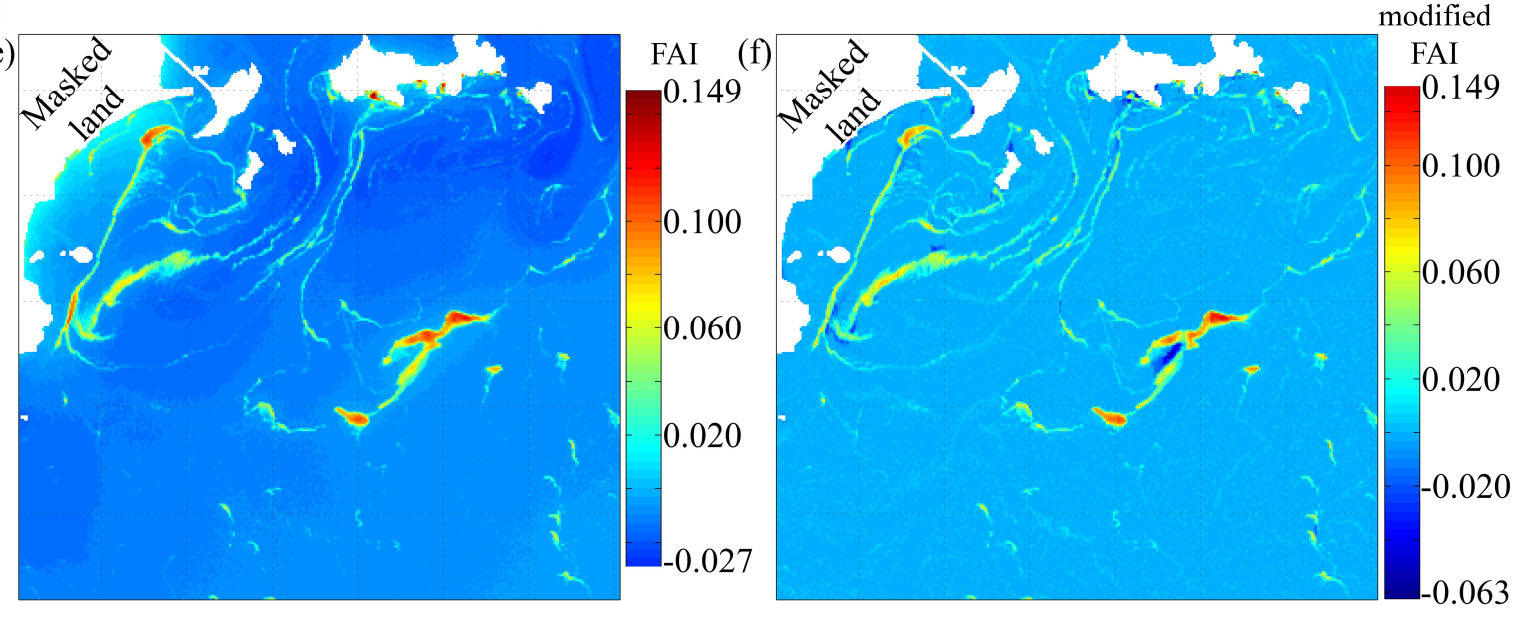

Figure 4. Comparison of macroalgae patches between Landsat- 8 based $(\mathbf{a}, \mathbf{b})$ are true colour RGB (bands $4,3,2$ ) images after applying different contrast stretches for better visibility of the macroalgae patches at different locations; (c) FAI and (d) modified FAI for the smaller ROI area (red rectangle in Figure 1) in path/row 119/35 on 25 July 2015. The colourmaps of FAI and modified FAI are shown as (e) and (f), respectively. 

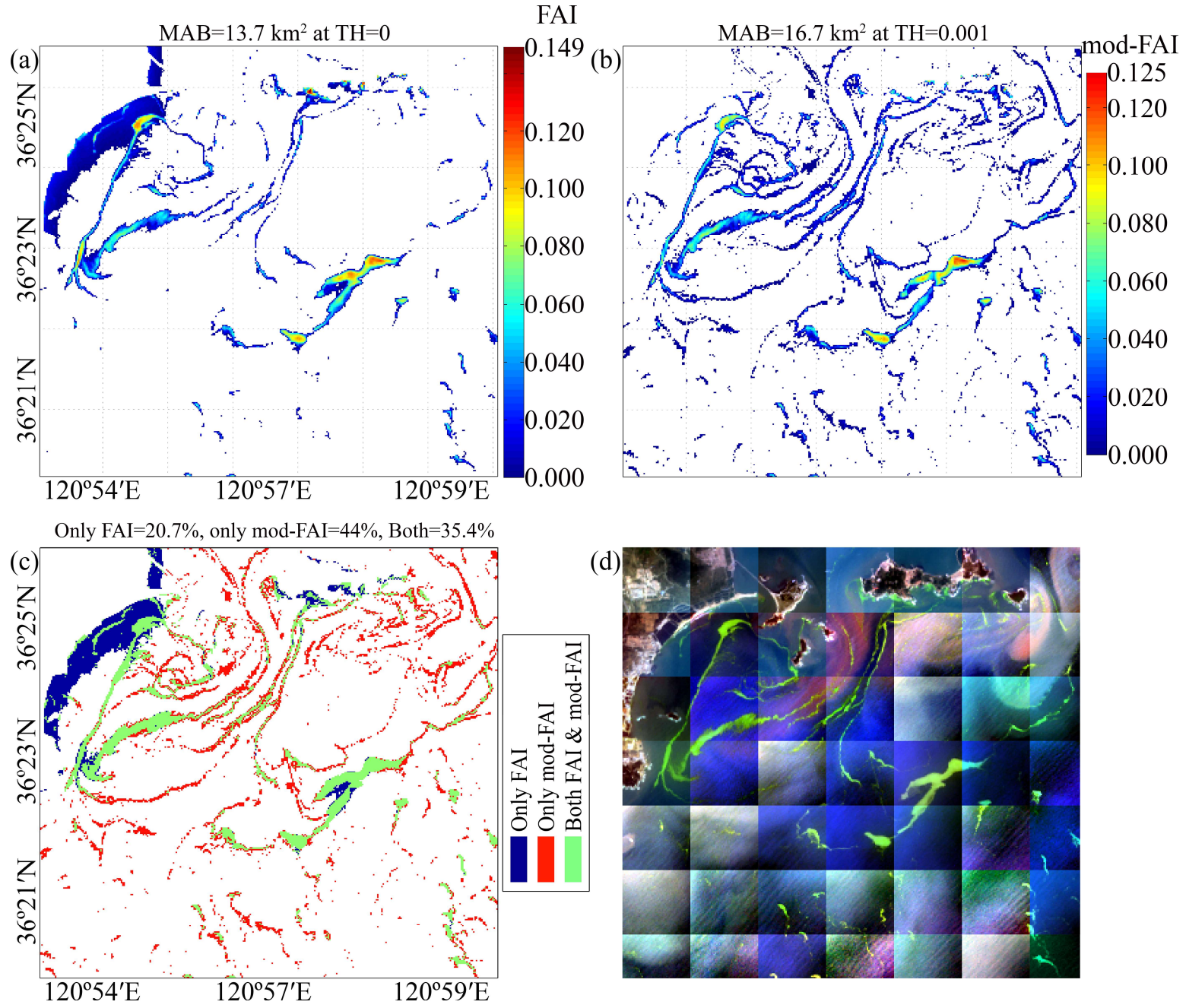

Figure 5. Landsat- 8 based macroalgae detection results for the ROI area in Figure 4 by (a) only FAI, (b) only modified FAI, and (c) combined detection results. For FAI and modified FAI threshold values of 0 and 0.001 , respectively, were used. Respective true colour composite RGB image is shown as (d) after applying different colour stretches to different portions of the image.

The changes in the distribution of macroalgae and sea pixel values due to the shift from FAI to mod-FAI for some images of different paths and rows covering the study areas are illustrated as histograms in Figure 8. Separate colours are used to differentiate the portion of macroalgae and sea pixels in each of the histograms for FAI and mod-FAI. In the process of histogram preparation, the pixels in the mod-FAI are grouped into macroalgae and sea through applying an image-specific threshold (shown by vertical hatch lines), and those pixel indices are used to group the macroalgae and sea pixels in the respective FAI images. In all images the numbers of sea pixels are shown in log scale to fit the histograms' $Y$ axis. In Figure 8a the results are shown for the ROI area in Figure 5. The rest of the histograms represent results for the whole image area except lands and clouds (excluding macroalgae under thin clouds). From the histograms it can be seen that although the thresholds for each image stay little above 0 , they are different for each image. Thus, in order to find out the suitable threshold value for each image the exclusion method [34] was applied rather than using a fixed-threshold value as is used in the FAI. 

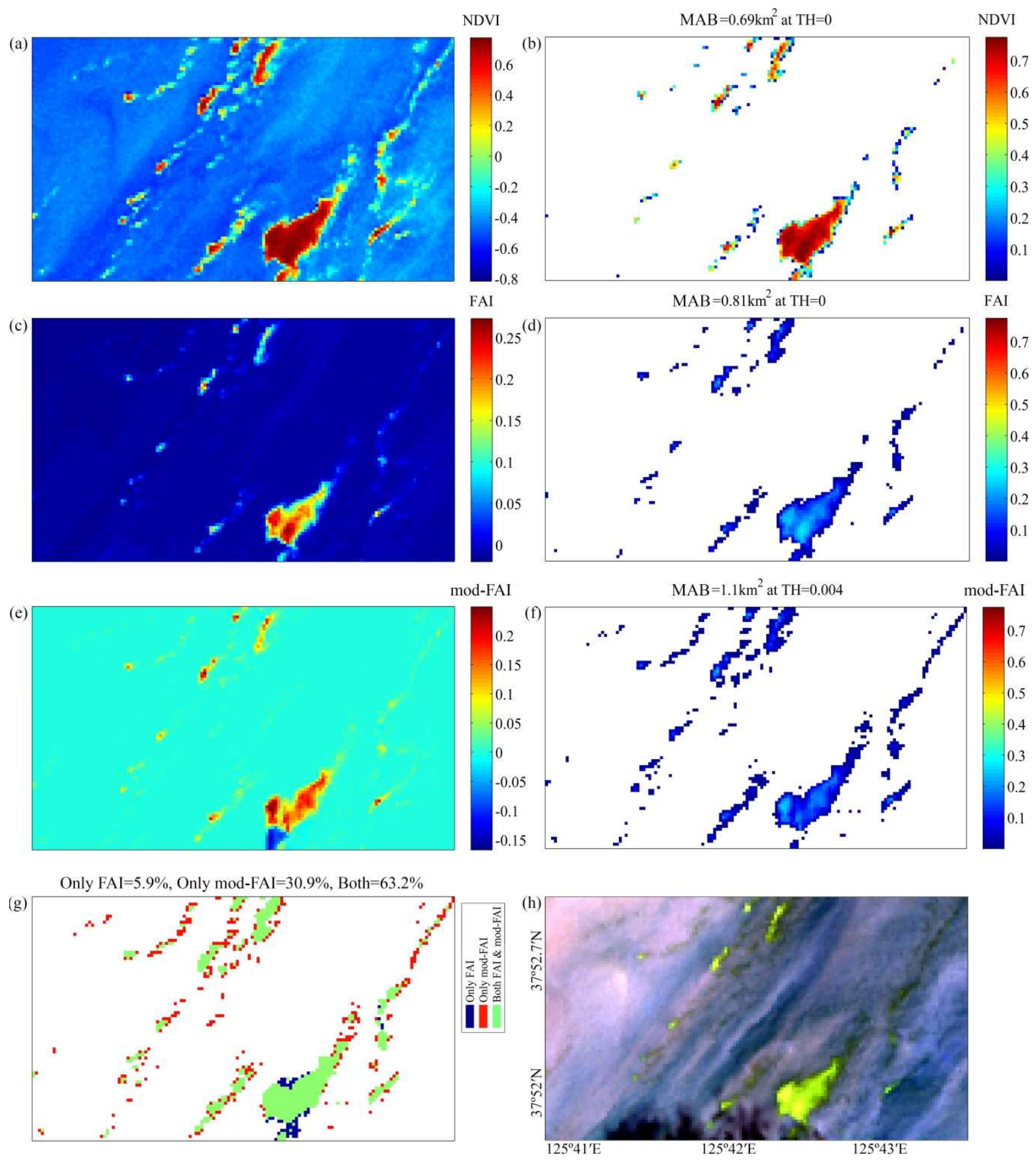

Figure 6. Comparison of Landsat- 8 based vegetation indices colourmaps of (a) NDVI, (c) FAI, and (e) modified FAI with the thresholding-based detected macroalgae in the corresponding vegetation indices (b,d, and $\mathbf{f}$, respectively) for the small ROI area (Figure 1) of path/row 116/34 on 2 August 2014 at 02:11 UTC. The respective (g) common as well as only FAI and modified FAI-based detection, and (h) the natural colour composite image (Landsat bands 4, 3, and 2) are also compared.

The modification of FAI showed better detection of the small patches of macroalgae and are thus applied to the images covering the study areas. The results of detection for some images covering the study areas are shown in Figures 9-11 after grouping into respective path/row. 

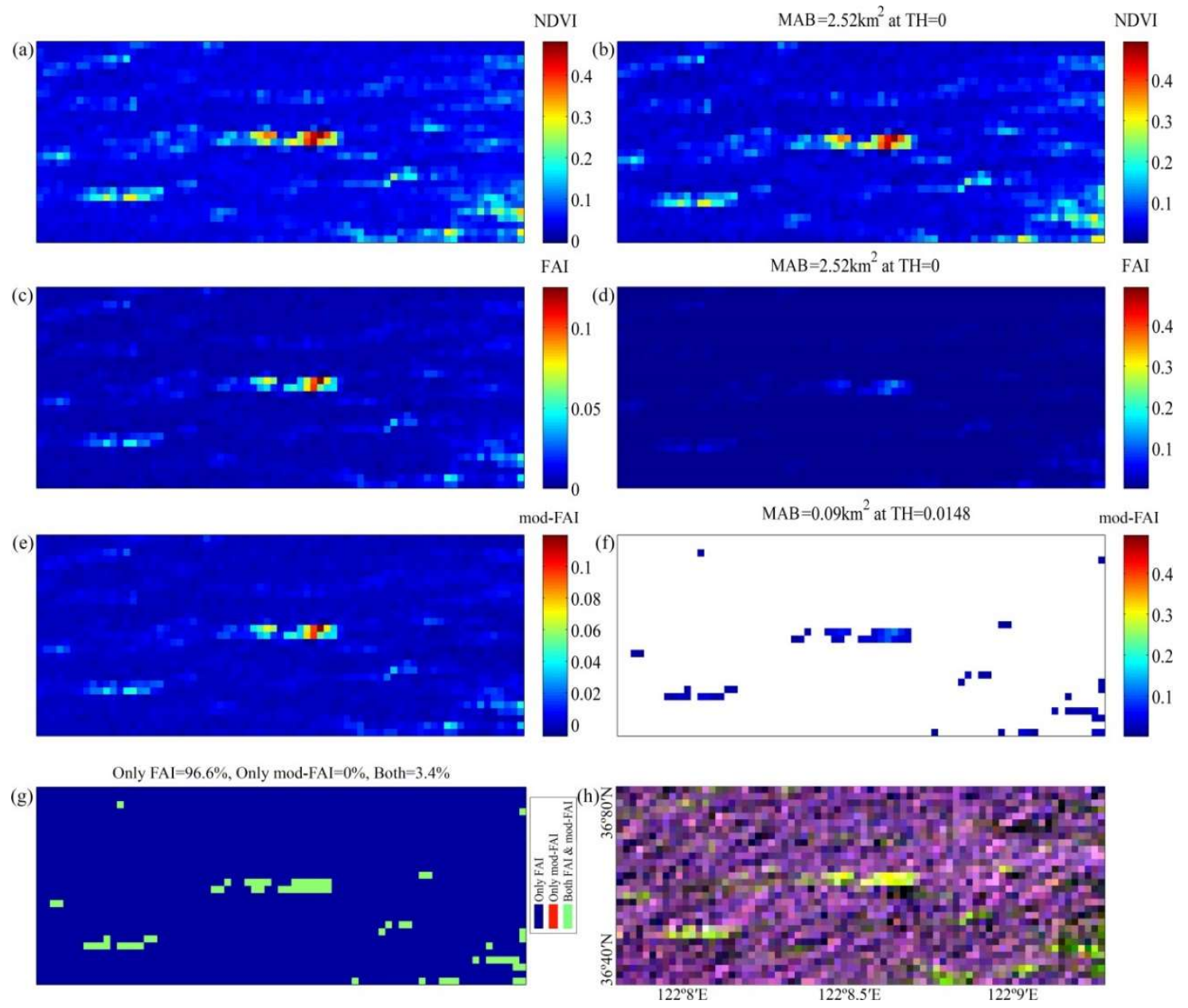

Figure 7. Comparison of Landsat- 8 based vegetation indices colourmaps of (a) NDVI, (c) FAI, and (e) modified FAI with the thresholding-based detected macroalgae in the corresponding vegetation indices (b,d, and f f, respectively) for the small ROI area (Figure 1) of path/row 119/34 on 25 June 2016 at 02:29 UTC. The respective (g) common as well as only FAI and modified FAI-based detection, and (h) the natural colour composite image (Landsat bands 4, 3, and 2) are also compared.
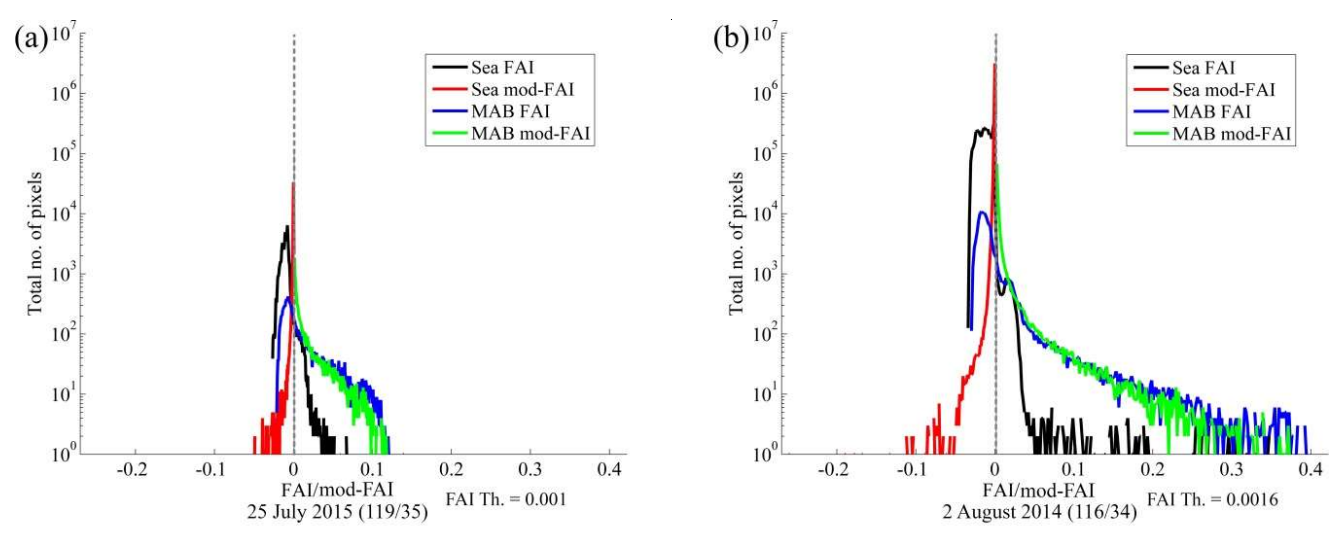

Figure 8. Cont. 

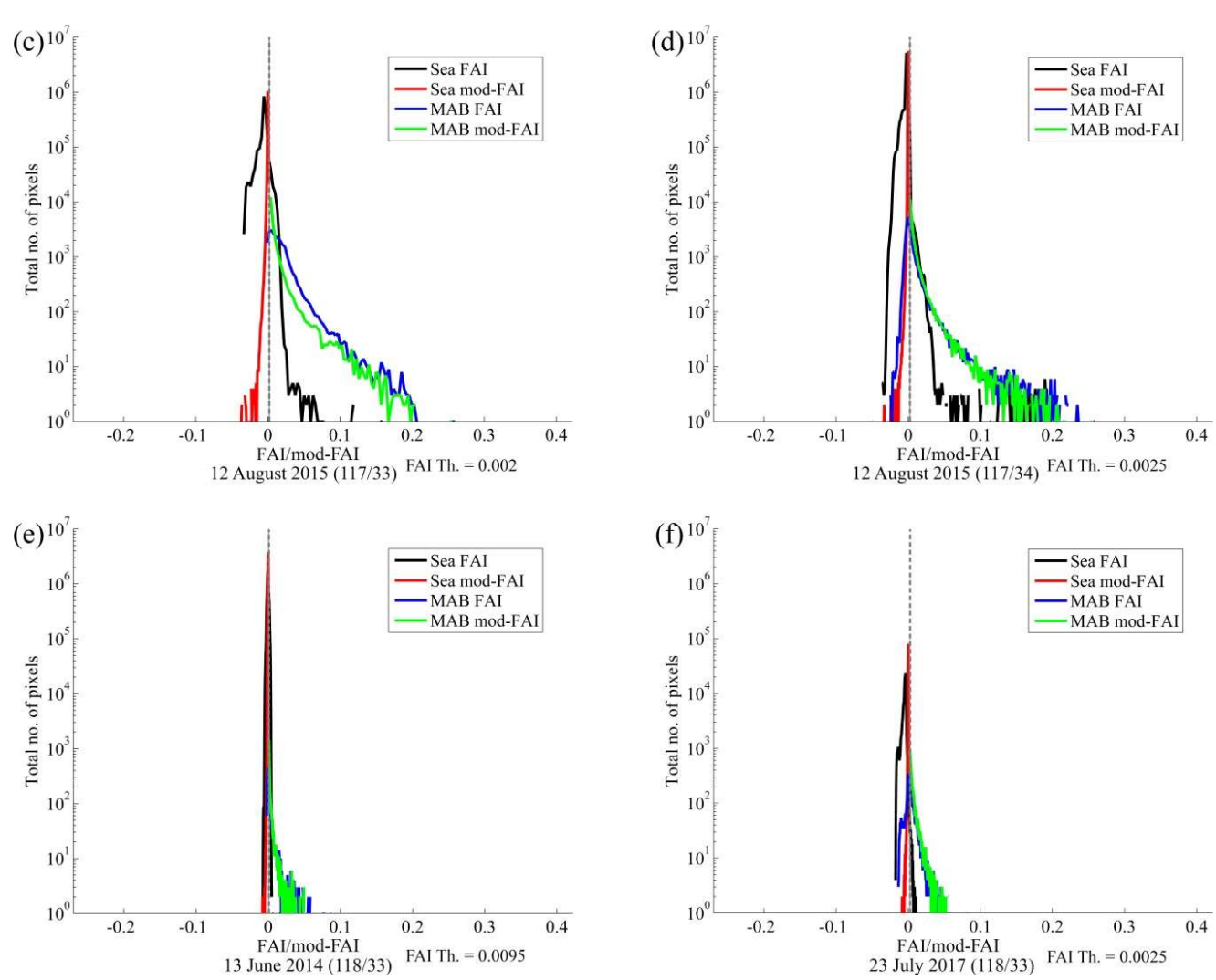

Figure 8. Changes in the distribution of macroalgae and sea pixels due to the application of modification to the FAI. Results of (b) to ( $\mathbf{f})$ are shown for the whole image areas of respective Landsat- 8 images except (a) showing the results for the area in Figure 4e,f. Vertical hatch lines are shown along the modified FAI threshold values (mod-FAI).
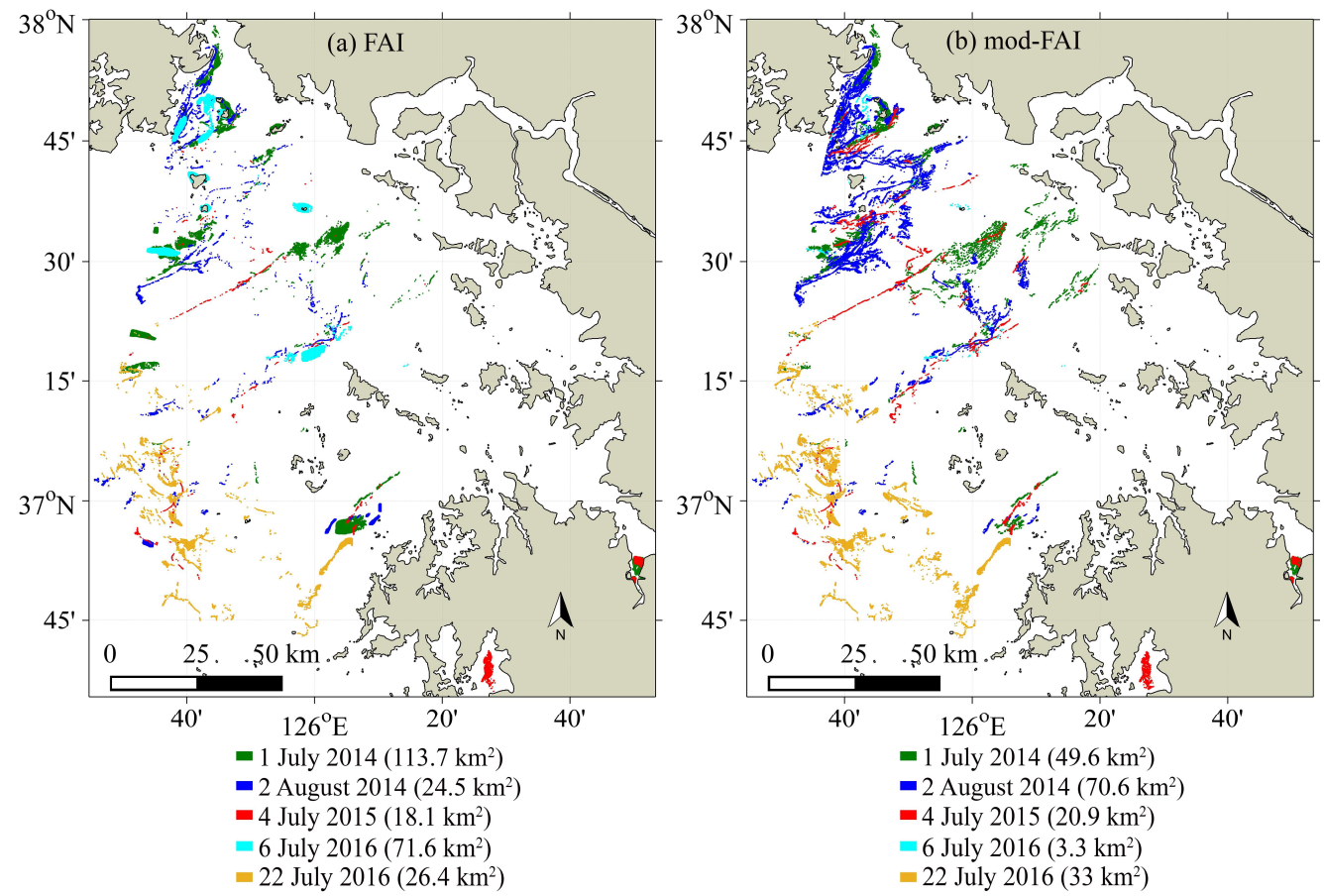

Figure 9. Detection results of macroalgae from Landsat-8 modified FAI images for path/row 116/34. Detected macroalgae pixels are exaggerated in size for better visibility. For the map area refer to the dashed rectangle in Figure 1. 


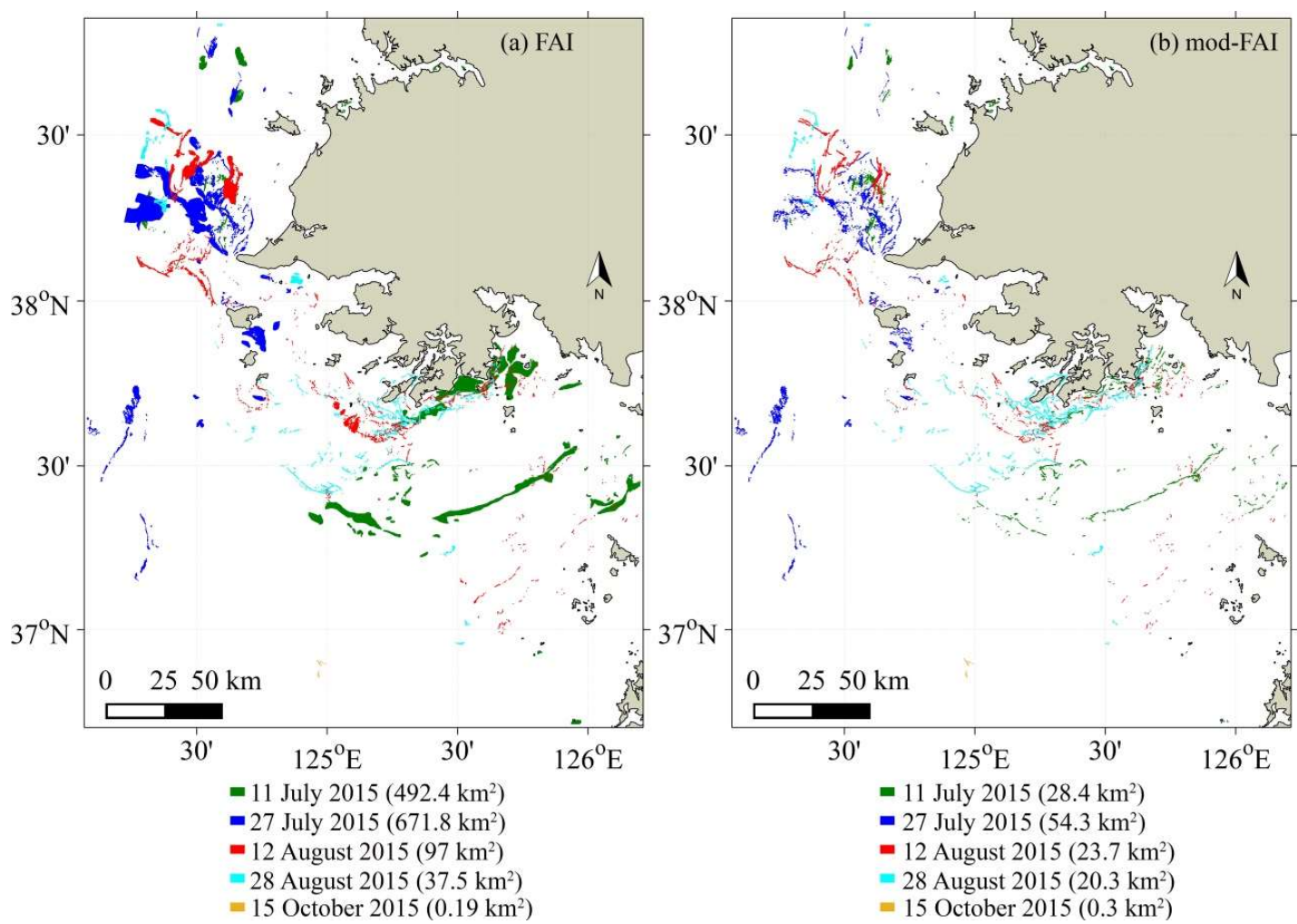

Figure 10. Detection results of macroalgae from Landsat-8 modified FAI images for path/row 117/33 and $117 / 34$. Detected macroalgae pixels are exaggerated in size for better visibility. For the map area refer to the largest dashed rectangle in Figure 1.
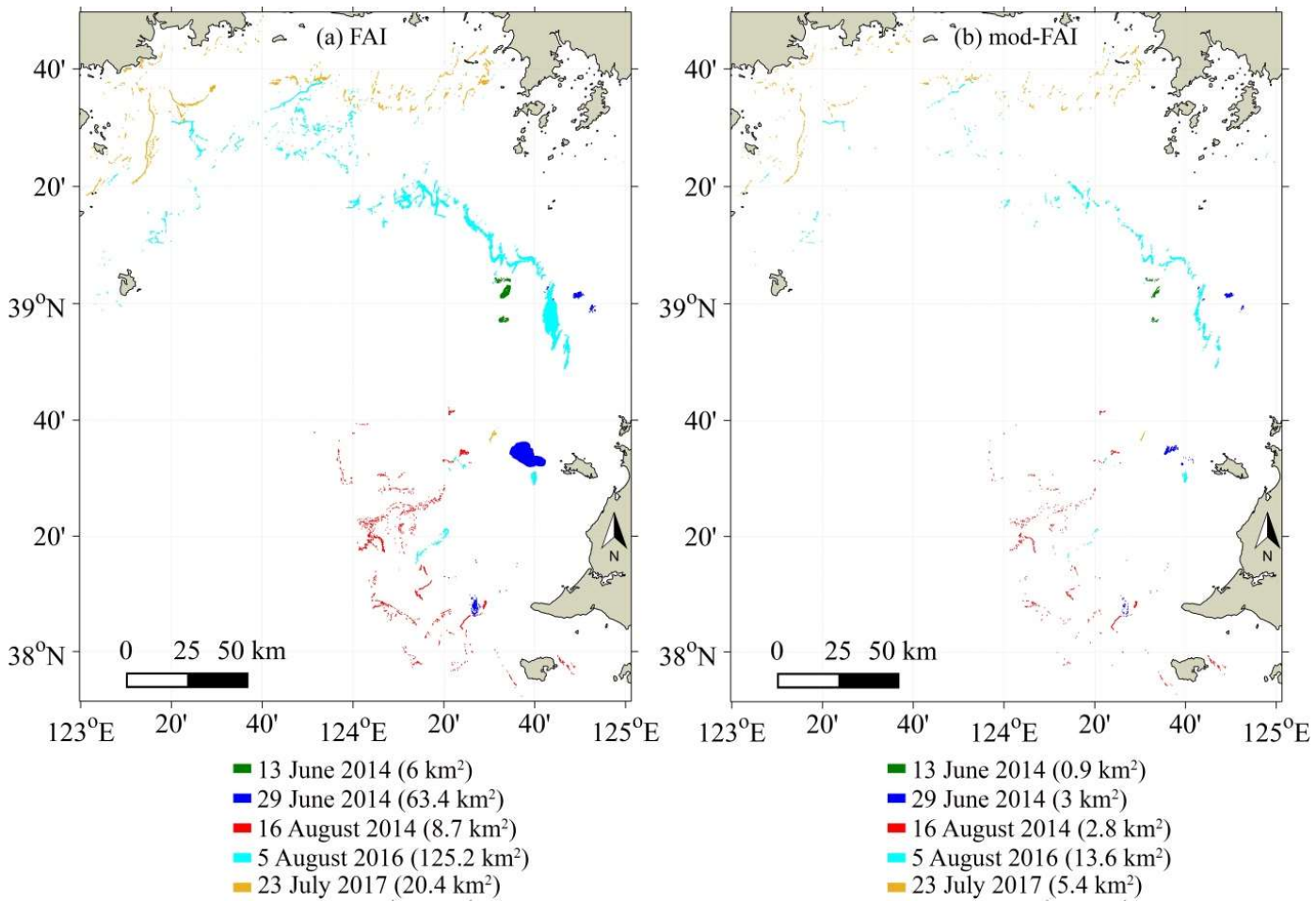

Figure 11. Detection results of macroalgae from Landsat- 8 modified FAI images for path/row 118/32 and $118 / 33$. Detected macroalgae pixels are exaggerated in size for better visibility. For the map area refer to the smaller dashed rectangle Figure 1. 


\section{Discussion}

From the results shown in Figure 4, it is found that the modification of FAI through contrast enhancement resulted in better distinction of macroalgae from the surrounding sea. The image pixel values for FAI and mod-FAI are shown as colourmaps in Figure 4e,f, respectively. From Figure 4e, we can see that the sea pixels have wide range of values (including positive ones) in different areas of the image. On the contrary, in the mod-FAI (Figure 4f) the values of the sea pixels are homogenized (decreased near to 0 ) for the whole area of the image. Thus, it became possible to differentiate the macroalgaes from the surrounding sea pixels by applying a single threshold value of 0.001 as described before. The detection results of macroalgae in the FAI, mod-FAI, and their comparative detection in the respective area are shown in Figure 5. From the individual detection results (Figure 5c) we can see that some large areas are incorrectly detected as macroalgae only by FAI (green patches). That erroneous detection happened due to the possession of positive FAI values by the hazy sea pixels (refer to the respective colourbar). However, most of the tiny patches that were not detected by the FAI are correctly detected by the mod-FAI (red patches). Actually, the pixel values of those thin and small macroalgae patches which were 0 or slightly negative in the FAI are considerably increased in the mod-FAI; thus it become possible to differentiate them by using a single threshold value for the whole image. Only for the small area (a few pixels along inside the large patch of macroalgaes around the centre of the figure), the mod-FAI could not detect macroalgae due to the decrease in values compared to the FAI, which can be considered as an exception. Thus, through this method considerably more macroalgae patches were still detected correctly. Therefore, it is found that using image dependent single threshold the mod-FAI produced better results of macroalgae detection with least or no false detection and successful detection of many small patches, which are also achieved from different images as clearly shown in Figures 6 and 7, and later on in Figures 9-11. Thus, in general it can be said that the proposed modification resulted in much better detection of macroalgae patches than that of FAI.

From Figure $8 \mathrm{a}$ it can be seen that that although most of the macroalgae and sea pixels from FAI have higher contrast, some sea and macroalgae pixels fall in the same range of FAI values from -0.02 to 0.048 . Thus, use of the threshold value 0 excludes many macroalgae pixels, especially many of the very small patches which in most cases have low FAI values (Figure $5 b$ ), and also includes some sea pixels in the macroalgae detection results. Therefore, many tiny macroalgae patches in the FAI image cannot be detected by applying a single threshold value. Here, the critical point is to differentiate the macroalgae pixels (Figure 8) which have values very close to 0 or negative in the FAI (blue lines at the left side of the hatch line which also include many sea pixels from erroneous detection), and also to exclude the open sea pixels which have positive values (magenta line at the right side of the hatch line). Due to the modification, the pixels in most of the small macroalgae patches with negative FAI values have shifted to positive values in the mod-FAI; thus, the minimum value of macroalgae pixels is 0.001 in the mod-FAI. The decrease in mod-FAI values for a few macroalgae pixels is also evident; however, this did not affect their differentiation from the sea because the values still remain above the sea pixel values. Moreover, all sea pixel values are homogenized; thus the sea pixels that possessed values higher than the FAI threshold have decreased and fall below the minimum value (threshold) of the macroalgae pixels in the mod-FAI. Therefore, better results were observed in the detection of small macroalgae patches. Similar trends in the shift of pixel values are also seen for the histograms of other sub-images (Figure 8b-f).

In previous work [10], we used GOCI NDVI for the detection of MAB in the YS. GOCI provides daily 8 images with a large coverage of oceanic areas including the YS. Thus, it became possible to suitably obtain information on their monthly distribution, coverage and hourly shift [10]. However, although the FAI produced better results of MAB detection than NDVI, we could not apply FAI on GOCI due to the lack of a SWIR band. Moreover, small patches of macroalgae could not be detected using $500 \mathrm{~m}$ spatial resolution GOCI. On the contrary, in spite of low temporal resolution Landsat-8 has two SWIR bands which allow FAI or the mod-FAI to be applied. The high resolution Landsat-8 
based mod-FAI facilitates detection of small macroalgae patches which acted as a key motivation of the current research. An example of such a comparison is shown in Figure 3. From that figure it is obvious that considerably more areas are detected as macroalgae, and tiny patches are also included in the detection result of mod-FAI. Thus, an area of around $214 \mathrm{~km}^{2}$ is detected as macroalgae by the mod-FAI in Landsat- 8 , whereas only $42 \mathrm{~km}^{2}$ area is detected as macroalgae by GOCI NDVI. From Figures 4 and 5 it can be seen that the pixel values of macroalgae were not very high for small macroalgae patches and also for the bordering pixels of larger patches; thus could not be detected from the GOCI NDVI.

As the mod-FAI produced better detection results of macroalgae than FAI and NDVI, we have applied this modified method on 33 images (Table 1) across Korea Bay and Gyeonggi Bay from 2014 to 2017. The macroalgae detection results in the mod-FAI in comparison to FAI are shown in Figures 9-11. The sizes of many tiny patches were too small to be seen properly in the figures; thus pixel sizes were exaggerated for better visualization. In Figure 9, the detection of macroalgae in Gyeonggi Bay and nearby sea areas (path/row 116/34) is shown. During the beginning of July 2014 many large macroalgae patches are detected in the mod-FAI images along the north of Gyeonggi Bay and some scattered patches outside the bay (in total around $50 \mathrm{~km}^{2}$ ). However, although the detection in the respective FAI is more than double, it is erroneous due to overdetection. After one month their coverage decreased and many tiny patches were detected in the mod-FAI image inside an estuary whereas most of those small patches could not be traced in the FAI; thus the detected area was also one third of mod-FAI based detection. In 2015 less coverage were detected, and patches were traced in the same estuary as were in the previous year. Moreover, the detection result in the mod-FAI is slightly larger than the FAI-based detection. In July 2016 a few tiny patches were detected in the mod-FAI image as few numbers scattered at various places in the bay, whereas fully erroneous overdetection in the respective FAI image is observed. This FAI-based macroalgae detection is obviously fully erroneous as it is almost 21 times greater than that of mod-FAI. However, the coverage increased considerably after 15 days and extended to an area of $33 \mathrm{~km}^{2}$. The detection results for Korea Bay and adjacent sea areas are shown in Figures 10 and 11. In Figure 10 the detection of macroalgae patches at the south of Korea Bay during 2015 is illustrated. From the mod-FAI based detection (Figure 10b), we can see that some long thin patches were detected in mid-July. At the end of July, more areas are found to be occupied by macroalgae, then decreased again in August. Thus, on 15 November only two small patches could be detected with no traces afterwards during that year in the Landsat- 8 images. However, in the sea area far south of Korea Bay, overdetection of macroalgae are observed for all dates of detection in FAI images (Figure 10a). Outside of Gyeonggi Bay region, overdetection on 11 July was much more than those of other dates. From the mod-FAI based macroalgae detection in Figure 11 it is obvious that a few tiny patches appeared in the centre of Korea Bay during July 2014 which did not grow much within the next half of the month. After one and half months, they occupied slightly more areas at south. In 2016, macroalgae were found to occupy larger areas. However, in 2017 more areas were occupied by macroalgae which approached more to the coasts than in previous years. Thus, every year very small patches are detected in the study areas similar to the time of MAB generation in the YS, an oceanic region far from the study areas. As were in previous figures, overdetection is observed here in the FAI based detection although the intensity was less in most of the areas. However, in the previous work [6] the first detection of macroalgae in 2015 in the YS was on 25 July, whereas the macroalgae in Korea Bay and nearby Gyeonggi Bay appeared almost at the middle of August in the same year. Similarly, some macroalgae patches outside Gyeonggi Bay in the next year were first detected in the very first week of August. In order to check the possibility of macroalgae patches being transported from the YS to the study areas, we have visually searched the high-resolution Landsat-8 RGB images as well as respective mod-FAI images in between these places. Thus, we have checked the path/row of the following images: whole images of 118/34,118/35,117/35, top and right areas of $119 / 34$, top right area of $119 / 35$, and left and bottom areas of $117 / 34$. Cloud free available images were searched in 2014 to 2017 in between the first detection of macroalgae in the YS to the first detection of macroalgae patches in the study areas. However, we could not find even a tiny patch of macroalgae 
in between these places. This study also identifies that the current detection of macroalgae in the mod-FAI was around one month earlier than GOCI NDVI-based detection and almost at the same time of the occurrence in the YS, although they occurred as patches too small to be detected by the $500 \mathrm{~m}$ GOCI-based NDVI [10].

\section{Conclusions}

In the previous study [10] some macroalgae patches were detected in Korea Bay, Gyeonggi Bay and adjacent waters by applying the commonly used vegetation index of NDVI on GOCI. The detected patches were smaller in size compared to macroalgae patches in the YS. However, much smaller patches (smaller than $500 \mathrm{~m}$ ) could not be detected properly. Therefore, in this study we concentrated our effort on the detection of tiny patches using high-resolution Landsat-8 images. Hence, by using a moving median filter the FAI is modified in order to increase the overall contrast between sea and macroalgae pixels which made it possible to discriminate tiny patches successfully by applying a scene-wide single threshold. Misdetection of sea pixels as macroalgae was also avoided compared to the original FAI. Thus, numerous tiny patches are detected in Korea Bay and Gyeonggi Bay in every June or July during the study periods. Within the next two months they bloomed and occupied comparatively larger areas. Their frequent existence as small patches and blooming in every summer indicate that they might have originated locally. Thus, the modification of FAI supported successful detection of tiny patches of macroalgae which would be helpful for the precise monitoring of macroalgae in optically complex waters.

Author Contributions: Conceptualization, Rashid A.H.A. and Yang C. S.; Methodology, Rashid A.H.A. and Yang C.S.; Software, Rashid A.H.A. and Yang C.S.; Validation, Rashid A.H.A. and Yang C.S.; Formal Analysis, Rashid A.H.A. and Yang C.S.; Investigation, Rashid A.H.A. and Yang C.S.; Resources, Rashid A.H.A. and Yang C.S.; Data Curation, Rashid A.H.A. and Yang C.S.; Writing-Original Draft Preparation, Rashid A.H.A.; Writing-Review and Editing, Rashid A.H.A. and Yang C.S.; Visualization, Rashid A.H.A. and Yang C.S.; Supervision, Yang C.S.; Project Administration, Yang C.S.; Funding Acquisition, Yang C.S.

Funding: This research received no external funding.

Acknowledgments: This research was supported by some projects titled 'Technology Development for Practical Applications of Multi-Satellite Data to Maritime Issues', 'Development of Ship-handling and Passenger Evacuation Support System', and 'Construction of Ocean Research Stations and their Application Studies' funded by the Ministry of Oceans and Fisheries, Korea.

Conflicts of Interest: The authors declare no conflict of interest.

\section{References}

1. Nelson, T.; Nelson, A.; Tjoelker, M. Seasonal and spatial patterns of "green tides" (ulvoid algal blooms) and related water quality parameters in the coastal waters of Washington State, USA. Bot. Marin 2003, 46, 263-275. [CrossRef]

2. Yabe, T.; Ishii, Y.; Amano, Y.; Koga, T.; Hayashi, S.; Nohara, S.; Tatsumoto, H. Green tide formed by free-floating Ulva spp. at Yatsu tidal flat, Japan. Limnology 2009, 10, 239-245. [CrossRef]

3. Morand, P.; Briand, X. Excessive growth of macroalgae: A symptom of environmental disturbance. Bot. Marin 1996, 39, 491-516. [CrossRef]

4. Teichberg, M.; Fox, S.E.; Olsen, Y.S.; Valiela, I.; Martinetto, P.; Iribarne, O.; Muto, E.Y.; Petti, M.A.V.; Corbisier, T.S.N.; Soto-Jimenez, M.; et al. Eutrophication and macroalgal blooms in temperate and tropical coastal waters: Nutrient enrichment experiments with Ulva spp. Glob. Chang. Biol. 2009. [CrossRef]

5. Ye, N.-H.; Zhang, X.-W.; Mao, Y.-Z.; Liang, C.-W.; Xu, D.; Zou, J.; Zhuang, Z.-M.; Wang, Q.-Y. 'Green tides' are overwhelming the coastline of our blue planet: Taking the world's largest example. Ecol. Res. 2011, 26, 477-485. [CrossRef]

6. Zhang, X.; Xu, D.; Mao, Y.; Li, Y.; Xue, S.; Zou, J.; Lian, W.; Liang, C.; Zhuang, Z.; Wang, Q.; et al. Settlement of vegetative fragments of Ulva prolifera confirmed as an important seed source for succession of a large-scale green tide bloom. Limnol. Oceanogr. 2011, 56, 233-242. [CrossRef] 
7. Keesing, J.K.; Liu, D.; Fearns, P.; Garcia, R. Inter- and intra-annual patterns of Ulva prolifera green tides in the Yellow Sea during 2007-2009, their origin and relationship to the expansion of coastal seaweed aquaculture in China. Mar. Pollut. Bull. 2011, 62, 1169-1182. [CrossRef] [PubMed]

8. Liu, D.; Keesing, J.K.; Xing, Q.; Shi, P. World's largest macroalgal bloom caused by expansion of seaweed aquaculture in China. Mar. Pollut. Bull. 2009, 58, 888-895. [CrossRef] [PubMed]

9. Xu, Q.; Zhang, H.; Cheng, Y. Multi-sensor monitoring of Ulva prolifera blooms in the Yellow Sea using different methods. Front. Earth Sci. 2015, 10, 378-388. [CrossRef]

10. Harun-Al-Rashid, A.; Yang, C.-S. Hourly variation of green tide in the Yellow Sea during summer 2015 and 2016 using Geostationary Ocean Color Imager data. Int. J. Remote Sens. 2018, 39, 4402-4415. [CrossRef]

11. Xing, Q.; Hu, C. Mapping macroalgal blooms in the Yellow Sea and East China Sea using HJ-1 and Landsat data: Application of a virtual baseline reflectance height technique. Remote Sens. Environ. 2016, 178, 113-126. [CrossRef]

12. Hu, C. A novel ocean color index to detect floating algae in the global oceans. Remote Sens. Environ. 2009, 113, 2118-2129. [CrossRef]

13. Chen, J.; Cui, T.; Tang, J.; Song, Q. Remote sensing of diffuse attenuation coefficient using MODIS imagery of turbid coastal waters: A case study in Bohai Sea. Remote Sens. Environ. 2014, 140, 78-93. [CrossRef]

14. Lü, X.; Qiao, F.; Xia, C.; Wang, G.; Yuan, Y. Upwelling and surface cold patches in the Yellow Sea in summer: Effects of tidal mixing on the vertical circulation. Cont. Shelf Res. 2010, 30, 620-632. [CrossRef]

15. Ryu, J.; Choi, J.; Eom, J.; Ahn, J. Temporal variation in Korean coastal waters using geostationary ocean color imager. J. Coastal. Res. 2011, 64, 1731-1735.

16. Jahan, R.; Choi, J.K. Climate change and eutrophication of coastal waters: Gyeonggi Bay long-term surveys. In Proceedings of the 15th International Conference on Harmful Algae, Changwon, Korea, 29 October-2 November 2012.

17. Chu, P.C.; Fralick, C.R.; Haeger, S.D.; Carron, M.J. A parametric model for the Yellow Sea thermal variability. J. Geophys. Res. Oceans 1997, 102, 10499-10507. [CrossRef]

18. Bhandari, S.; Phinn, S.; Gill, T. Preparing Landsat Image Time Series (LITS) for monitoring changes in vegetation phenology in Queensland, Australia. Remote Sens. 2012, 4, 1856-1886. [CrossRef]

19. Shang, J.; Liu, J.; Huffman, T.; Qian, B.; Pattey, E.; Wang, J.; Zhao, T.; Geng, X.; Kroetsch, D.; Dong, T.; et al. Estimating plant area index for monitoring crop growth dynamics using Landsat- 8 and RapidEye images. J. Appl. Remote Sens. 2014, 8, 085196. [CrossRef]

20. RBINS. ACOLITE. Available online: https://odnature.naturalsciences.be/remsem/software-and-data/acolite (accessed on 2 June 2018).

21. Vanhellemont, Q.; Ruddick, K. Turbid wakes associated with offshore wind turbines observed with Landsat 8. Remote Sens. Environ. 2014, 145, 105-115. [CrossRef]

22. van der Zande, D.; Vanhellemont, Q.; De Keukelaere, L.; Knaeps, E.; Ruddick, K. Validation of Landsat-8/OLI for ocean colour applications with AERONET-OC sites in Belgian coastal waters. In Proceedings of the Ocean Optics Conference, Victoria, BC, Canada, 23-28 October 2016.

23. Vermote, E.; Tanré, D.; Deuzé, J.; Herman, M.; Morcrette, J.; Kotchenova, S. Second simulation of a satellite signal in the solar spectrum-vector (6SV). $6 S$ User Guide Version 2006, 3, 1-55.

24. USGS. Available online: https:/ / earthexplorer.usgs.gov/ (accessed on 2 June 2018).

25. Sayed, G.I.; Ali, M.A.; Gaber, T.; Hassanien, A.E.; Snasel, V. A hybrid segmentation approach based on neutrosophic sets and modified watershed: A case of abdominal CT liver parenchyma. In Proceedings of the 11th International Computer Engineering Conference (ICENCO), Cairo, Egypt, 29-30 December 2015.

26. Bernstein, R. Adaptive nonlinear filters for simultaneous removal of different kinds of noise in images. IEEE Trans. Circ. Syst. 1987, 34, 1275-1291. [CrossRef]

27. Giron, A.D.R.; Correa, H.L. Non-uniform heating compensation for sequences of thermal images using median filtering. Dyna 2013, 80, 74-82.

28. Gonzalez, R.C. Digital Image Processing; Prentice Hall: Upper Saddle River, NJ, USA, 2016.

29. Russ, J.C. The Image Processing Handbook; CRC Press: Boca Raton, FL, USA, 2016.

30. Young, I.T.; Gerbrands, J.J.; Van Vliet, L.J. Fundamentals of Image Processing; Delft University of Technology: Delft, The Netherlands, 1998.

31. Selvalakshmi, V.M.; Devi, S.N. A novel region based segmentation of hepatic tumors and hepatic vein in low contrast CTA images using Bernstein polynomials. Biomed. Res. India 2017, 28, S324-S331. 
32. Stephens, D.B.; Vold, H. Order tracking signal processing for open rotor acoustics. J. Sound. Vib. 2014, 333, 3818-3830. [CrossRef]

33. Kim, S.; Fu, X.; Wang, X.; Ishii, M. Development of the miniaturized four-sensor conductivity probe and the signal processing scheme. Int. J. Heat Mass Transf. 2000, 43, 4101-4118. [CrossRef]

34. Garcia, R.A.; Fearns, P.; Keesing, J.K.; Liu, D. Quantification of floating macroalgae blooms using the scaled algae index. J. Geophys. Res. Oceans 2013, 118, 26-42. [CrossRef] 